\title{
De víctima a victimario: la transformación de la protagonista en "Modesta Gómez" de Rosario Castellanos
}

\author{
DOLORES GutiÉRREZ*
}

\section{Resumen:}

Este artículo aborda la transformación de la protagonista en el cuento "Modesta Gómez" de la escritora Rosario Castellanos, en el cual una niña mestiza pasa de ser víctima de constantes agravios y humillaciones a ser victimario. El hecho de no ser indígena le permite abusar del que está por debajo de ella en la estructura social. De acuerdo con la teoría de la identidad narrativa de Paul Ricoeur, los personajes varían de una identidad idem a una identidad ipse y, en este caso, el personaje en su transformación transgrede el paradigma que le corresponde como mujer mexicana de baja condición social, lo que representa una doble transgresión: de género y social.

\section{Palabras clave:}

Modesta Gómez, Rosario Castellanos, identidad narrativa, transgresión, transformación.

Según el filósofo francés Paul Ricoeur, los personajes de la narrativa moderna reflejan la complejidad del ser humano actual que se modifica junto a un entorno que sufre constantes cambios. Durante

\footnotetext{
${ }^{*}$ Colegio Marymount.
} 
la lectura de un relato, se observa cómo los personajes van acumulando rasgos y realizando acciones que permiten definirlos; pero es hasta la conclusión del texto que es posible tener una percepción completa. Ricoeur afirma que la narrativa contemporánea se ha convertido en una especie de laboratorio donde la identidad del personaje se encuentra sometida a un número ilimitado de "variaciones imaginativas" y su transformación es de especial relevancia (348). El filósofo distingue la identidad idem de la identidad ipse: la primera plantea lo constante en el personaje, mientras la segunda marca lo mutable. La identidad narrativa muestra al individuo como agente; no solo abarca al autor de la acción, también a la acción misma, es decir, lo que hacemos es constitutivo de nuestra identidad. La acción contada también define la identidad narrativa, la cual tiene un sentido dinámico (Martínez 195). Es a partir de una narración que se construyen esas dos identidades; la identidad idem es una noción sustancialista que se define como la caracterización del personaje, a lo largo del relato aparecen elementos que definen cómo es ese personaje antes de tranformarse. La identidad ipse es prácticamente esa caracterización que a lo largo del relato sufre una serie de mutaciones (Tornero 150). La observación de los cambios del personaje a través de sus acciones, permite hablar de la identidad ipse. Y no es que se elimine a la otra, sino que se pone a prueba y va variando su estado original. La transformación de la identidad del personaje o la identidad ipse solo puede concretarse a través de la interpretación del lector (Ricoeur 341, 342).

En este artículo se analizará la transformación de la protagonista del cuento "Modesta Gómez", donde pasa de una condición a otra: de víctima a victimario, al transgredir el paradigma que le coresponde como mujer de una condición social baja. Para cumplir con este objetivo consideraré cuatro aspectos básicos del análisis narrativo: el papel del narrador y las dimensiones espacial, temporal y actorial (Pimentel 22). 


\section{Ciudad Real}

"Modesta Gómez" es uno de los diez cuentos que componen el libro Ciudad Real de la escritora chiapaneca Rosario Castellanos, publicado en 1960. Este volumen, con las novelas Balún Canán y Oficio de Tinieblas, surgió en la etapa en que la escritora regresó hasta Chiapas en 1956, para trabajar en el Instituto Indigenista. Particularmente en Ciudad Real plasma sus experiencias de esa época. No sitúa sus historias en Comitán, lugar de su infancia, sino en San Cristóbal de las Casas. Cabe preguntarse por qué usó para el volumen el nombre de Ciudad Real, que es el nombre de San Cristóbal de las Casas en la época de la Colonia, y coincido con Ezequiel Maldonado, quien afirma que este título emblemático marca la permanencia de las prácticas abusivas de la Colonia y de las grandes contradicciones sociales (128). Llamar la ciudad con su nombre colonial es una forma de comunicar que la estructura social de esa época permanece. Los cuentos muestran las injusticias cometidas contra los indígenas y sus comunidades; en los distintos relatos aparecen imágenes que sugieren la pobreza en la que se desarrolla la cotidianidad de estos pueblos carentes de lo indispensable: "Encuclillados, los indios se espulgaban pacientemente y comían los piojos" (Castellanos, Ciudad 21). Mujeres e indios aparecen en los relatos como personajes expuestos a la infamia, son víctimas del abuso, pero un abuso consumado por una disposición de parte de ellos a que este se realice.

Los cuentos de Ciudad Real tienen algunos aspectos en común y dan una visión general sobre la coexistencia de las distintas etnias que confluyen en la región a partir de la Colonia; su gran acierto es que lo hacen a través de diversas perspectivas.

\section{"Modesta Gómez"}

Ya en el título anuncié que la protagonista se transforma al abandonar el papel de víctima para convertirse en victimario. Esta mutación transgrede la identidad que le correspondía por su condición social y su condición de género: una mujer mestiza a quien 
una vida llena de infortunios la había dejado sola con la obligación de mantener a tres hijos. Su ubicación espacial y temporal perfila un ser sumiso, depositario de injusticias y vejaciones, quien debe aceptar resignadamente un destino determinado. Las circunstancias que rodean a Modesta la condenan a la inmovilidad, por tanto, su transformación de víctima a victimario rompe con el paradigma femenino que le corresponde. Castellanos escribió que:

Las mujeres en México llegan a unos límites de gusto por la autoinmolación que sobrepasan en mucho las nociones corrientes de la dignidad de la persona humana. Funcionan bajo otro signo de valor: el de sacrificio, la abnegación, máscaras bajo las cuales se esconde una realidad evidente: el placer se encuentra en ser humillada, escarnecida y ocupar en todas las ocasiones posibles el sitio de la víctima (Declaración 114).

La historia relata la vida de una mujer mestiza de baja condición social que es abandonada por sus padres en la casa de los Ochoa, una familia adinerada de Ciudad Real; ahí transcurre su infancia hasta que es despedida por engendrar un hijo de Jorgito, el hijo de los patrones. Una vez fuera de la casa, se casa con un albañil, quien le da nombre a la criatura y con el que tiene otros dos hijos. Este hombre borracho y golpeador muere y la deja sola con los tres niños. Ella empieza a trabajar en una carnicería, pero su sueldo no es suficiente, por lo que decide tomar el oficio de atajadora, a través del cual las mujeres ladinas esperan a los indios que vienen a la ciudad a vender sus mercancías y los interceptan para robárselas.

De acuerdo con la hermenéutica de Ricoeur, es posible afirmar que la identidad idem de la protagonista es la que se presenta al inicio de la historia: una niña, abandonada por sus padres, ingenua y dispuesta a aceptar todas las vejaciones. De esta identidad el lector podría esperar continuidad, por sus circunstancias; sin embargo, a lo largo del relato, la niña crece y los acontecimientos modifican al personaje. Modesta asume una identidad distinta al modelo que le corresponde, es decir, el personaje no se mantiene idéntico a sí 
mismo, sino que su identidad se transforma y ella deja de ser quien se perfilaba al inicio del relato.

\section{La falta de neutralidad en el narrador omnisciente}

La historia tiene un narrador heterodiegético con focalización cero, conocido también como narrador omnisciente; aunque su perspectiva se centra principalmente en la protagonista, va y viene en el tiempo y también conoce información que proviene del interior de otros personajes. La posición del narrador fuera de la diégesis presupone un tono neutro, sin embargo, sus juicios en el discurso narrativo, casi siempre disimulados, develan una postura frente a los sucesos. Uno de estos juicios puede verse cuando corren a Modesta de la casa de los Ochoa por su embarazo, el narrador describe al padre de Jorgito "congestionado de gordura, con sus ojos lúbricos", y al rostro de las tres hermanas, "con una ligera palidez de envidia", es decir, sugiere al lector que el padre era un hombre lujurioso y sus tres hijas sentían envidia por el estado de la joven sirvienta, en el justo momento en que es humillada. No deja de ser una crítica velada a los anhelos de estas mujeres que se ven a sí mismas en una soltería que les estorba, y al padre como el hombre que debe limitar su apetito sexual a la mirada. Los juicios del narrador se ven con mayor claridad cuando este hace uso de la ironía para hacer apreciaciones sobre las cualidades o acciones de sus personajes. Un ejemplo es cuando afirma: "Gracias a la violación de Modesta, Jorgito pudo alardear de hombre hecho y derecho" (Castellanos, Ciudad Real 68). Este enunciado donde "agradece" un acto tan cobarde como una violación, es en realidad una burla a la hombría de Jorgito, una crítica indirecta del narrador que solo un lector implícito puede descifrar. Otro ejemplo se da cuando Modesta escucha a unas mujeres hablando de su marido, afirmando que había muerto "de bolo" (borracho). El narrador señala cuál es el pensamiento de la protagonista en ese momento: 
¡Calumnias! Su marido no había muerto así. Bueno, era verdad que tomaba sus tragos y más a últimas fechas. Pero el pobre tenía razón. Estaba aburrido de aplanar las calles en busca de trabajo. Nadie construye una casa, nadie se embarca en una reparación cuando se está en pleno tiempo de aguas. Alberto se cansaba de esperar que pasara la lluvia, bajo los portales o en el quicio de una puerta. Así fue como empezó a meterse en las cantinas. Los malos amigos hicieron lo demás. Alberto faltaba a sus obligaciones, maltrataba a su familia. Había que perdonarlo. Cuando un hombre no está en sus cabales hace una barbaridad tras otra (Castellanos, Ciudad Real 70).

A simple vista la crítica, totalmente irónica, se dirige al marido; sin embargo, el narrador va más lejos, porque a través del párrafo anterior pone en evidencia la ceguera de la protagonista. Ahí el personaje, pese a todas las peripecias ha vivido, sigue mostrando una enorme ingenuidad.

El discurso del narrador se mezcla con el discurso figural directo e indirecto, este último es aquel que nace de la conciencia de los personajes (Pimentel 84); hay un frecuente uso de modismos chiapanecos, lo que contribuye a acentuar el carácter regional del texto: "Me ajenaron desde chiquita", "le daba chaveta", "era ya una varejoncita"; el mismo concepto de oficio de atajadora, es también propio del lugar. El discurso figural solo se da en las mujeres de la historia y aparece como una polifonía de voces femeninas en donde el narrador deja ver sus distintos puntos de vista o sus posiciones sociales. Parece un recurso encaminado a situar estereotipos cuya finalidad es la de cumplir una función específica dentro del mundo del texto. El lector logra reconocerlos porque encuentra elementos que reflejan su propio entorno. Un ejemplo es cuando doña Romelia, la patrona y mamá de Jorgito, escucha llorar al niño; ella le habla así a su hijo:

-¿Qué te hicieron, cutushito, mi consentido? Sin suspender el llanto Jorgito señalaba a Modesta.

- ¿La cargadora?, se cercioraba la madre. Le vamos a pegar 
para que no te resmuela. Mira, un coshquete aquí, en la mera choya; un jalón de orejas y una nalgada. ¿Ya estás conforme, mi puñito de cacao, mi yerbecita de olor? Bueno, ahora me vas a dejar ir, porque tengo mucho que hacer (Castellanos, Ciudad Real 66).

Esta forma de tratar al niño y los términos con los que se refiere a él muestran el tipo de madre que es doña Romelia. Caracterización que se refuerza, cuando se hizo la desentendida al saber que su hijo tenía relaciones con la muchacha. El narrador muestra a través de un discurso figural indirecto la manera de pensar del personaje: "Al fin y al cabo Jorgito era un hombre, no un santo; estaba en la mera edad en que se siente la pujanza de la sangre. Y de que se fuera con las gaviotas (que enseñan malas mañas a los muchachos y los echan a perder) era preferible que encontrara sosiego en su propia casa" (68). Su hipocresía e iniquidad se ponen de manifiesto cuando corre a Modesta: "Malagradecida, tal por cual. Tenías que salir con tu domingo siete. ¿Y qué creíste? ¿Qué te iba yo a solapar tus sinvergüenzadas? Ni lo permita Dios. Tengo marido a quien responder, hijas a las que debo dar buenos ejemplos. Así que ahora mismo te me vas largando a la calle" (69).

La inclusión de este discurso evidencia la posición crítica del narrador hacia el personaje. En Romelia no hay un cambio, permanece en su identidad idem. Ella representa el ejemplo de la mujer que perpetúa la sociedad patriarcal en nombre de la moral cristiana y de las buenas costumbres. Su alusión a Dios y a los buenos ejemplos al momento de echar a la calle a una mujer que ha sido violada por su hijo y que lleva una criatura en el vientre, representa una crítica feroz al estereotipo que representa doña Romelia. Cuando consiente que el hijo vaya con Modesta en lugar de con "las gaviotas" para saciar sus deseos, es una forma de aprobar que la muchacha es un objeto y su cuerpo tiene la función social de satisfacer al varón; sin embargo, este aspecto no se exterioriza, queda en su pensamiento, y es el narrador quien lo da a conocer. Cuando aparecen las consecuencias corre a la joven como si ella fuera la única responsable. Doña Romelia manifiesta un paradigma femenino propio de la 
moral religiosa y patriarcal: la mujer como incitadora del mal que provoca el pecado como Eva lo hizo con Adán. De acuerdo con este patrón la mujer es la única responsable de un embarazo y le corresponde a ella cargar con todas las consecuencias.

\section{La dimensión espacial: un elemento significante}

La dimensión espacial define el espacio diegético, los lugares del relato, es decir, el entorno en el que se desarrolla la historia y que se construye a través de las descripciones del discurso narrativo; puede presentarse como un espacio físico y/o social que da significación a quienes interactúan en él.

Antes se dijo que en el título del volumen hay una intención que convierte el lugar en un espacio significante. Monique Sarfati-Arnaud en su artículo 'Los 'buenos' y los 'malos' en 'Modesta Gómez’: lectura ideológica de un cuento de Rosario Castellanos", fundamenta su análisis en un modelo escénico basado en las prácticas mercantiles latinoamericanas. De acuerdo con este, el relato se divide en tres actos en los que se realiza un intercambio mercantil y cada uno concluye cuando el personaje-víctima se ve obligado a salir del escenario. En el primer acto, el escenario es la casa de los Ochoa, la mercancía es la protagonista y su estancia ahí la convierte en víctima por el trato que le dan. Es expulsada en forma humillante cuando se evidencia su embarazo. En el segundo acto, el escenario es el mercado donde se encuentra la carnicería de doña Agueda, ahí, en la venta de la carne, se estafa al indio a quien se le da la carne podrida y con granos, además de alterar la balanza para timarlo; la más mínima protesta de la víctima provoca tal escándalo, que el indígena huye atemorizado por las amenazas de la multitud. El escenario del tercer acto es la salida de Moxviquil, donde las atajadoras aguardan a los indios. En él, la indígena, a quien Modesta le arrebata el chamarro, golpeándola y rasguñándola, huye presurosamente después de recoger la moneda que la otra atajadora le lanzó por su mercancía (705-07). Sarfati-Arnaud concluye: 
El análisis de los tres actos propuestos por el modelo escénico ha permitido revelar el mecanismo de las prácticas mercantiles en un país latinoamericano después de la conquista. Ahora bien, el hecho de que la heroína del relato, Modesta Gómez, pase de víctima en el primer acto a victimario en el segundo y tercer actos, aparte de romper con la tradicional dicotomía buenos vs. malos, permite apreciar el grado de asimilación y de reproducción mimética de la ideología dominante por un sector marginado de la sociedad mexicana representado aquí por las ladinas (707).

La lectura del cuento "Modesta Gómez" permite diversos análisis así como la creación de distintos modelos que se enfocan en el mismo punto: la explotación tanto en el ámbito social como en situaciones de género. El modelo escénico de Sarfati-Arnaud es una de las posibles lecturas, sin embargo, el texto admite otras, orientadas de manera distinta. Mi análisis de la dimensión espacial está fundamentado en el carácter emblemático de la ciudad como centro de una estructura social de explotación. Los distintos lugares que aparecen en el relato están en ella y son espacios en donde se dan relaciones de abuso y desigualdad. De acuerdo con esa visión se puede dividir el cuento en tres espacios diferenciados por tres estructuras de explotación distintas:

El primero, la casa de los Ochoa, donde la explotación está determinada por la clase social que radicaliza la posición de dos grupos: los patrones y los sirvientes. La familia Ochoa la componen don Humberto, doña Romelia, tres hijas y Jorgito. Modesta llega como sirvienta a esa casa arrastrada por la pobreza de sus padres; las primeras humillaciones las recibe de las otras sirvientas, quienes reproducen la ideología de los patrones, porque es el comportamiento que les exige su empleo:

Las criadas recibieron con hostilidad a la patoja y, al descubrir que su pelo hervía de liendres, la sumergieron sin contemplaciones en una artesa llena de agua helada. La restregaron 
con raíz de amole, una y otra vez, hasta que la trenza quedó rechinante de limpia.

-Ahora sí, ya te podés presentar con los señores. De por sí son muy delicados (Castellanos, Ciudad Real 66).

A nadie le preocupó que Modesta no hubiera acabado de crecer para cargar al niño de la casa, que prácticamente era de su misma edad, ese descuido hizo que se le torcieran las piernas. Ella jugaba con Jorgito, sin embargo, esta intimidad de la niñez en la que hicieron travesuras juntos, no acababa con las grandes diferencias que había entre ellos: "Es tu patrón... y con los patrones nada de confiancitas”, le decía doña Romelia (67). Cuando Jorgito la violó, en un principio ella opuso resistencia, pero cuando lo reconoció ya no hizo nada para impedirlo: "Ella y su adversario forcejeaban mientras las otras mujeres dormían a pierna suelta. En una cicatriz del hombro Modesta reconoció a Jorgito. No quiso defenderse más. Cerro los ojos y se sometió" (68). Finalmente ella estaba acostumbrada a ser el objeto de diversión del niño de la casa.

El segundo espacio, su matrimonio con el albañil Alberto Gómez, también representa una estructura social de explotación: "los años que Modesta duró casada con Alberto fueron años de penas y de trabajo. Verdad que en sus borracheras el albañil le pegaba, echándole en cara el abuso de Jorgito...” (71). Situación que es aceptada y justificada por la protagonista, porque ella misma señala que hay que perdonarlo porque no está en sus cabales (70). El que ella aceptara esos tratos obedecía a una gratitud, él la había apoyado en el momento más difícil, pero sobre todo por esa facultad masculina de darle valor social a una mujer: "Pero Alberto había valido a Modesta en la mejor ocasión: cuando todos le voltearon la cara para no ver su deshonra. Alberto le había dado su nombre y sus hijos legítimos, la había hecho una señora. ¡Cuántas de estas mendigas enlutadas, que ahora murmuraban a su costa, habrían vendido su alma al demonio por poder decir lo mismo!" (71).

Esa estructura de explotación está determinada por los valores de la sociedad patriarcal donde las mujeres asumen el papel de víctimas y se someten a tal condición con absoluta inercia, aceptando 
sus valores como propios. En el análisis que hace Sandoval Ventura de las mujeres en la narrativa de Rosario Castellanos, señala que "el esposo confiere valor social a la mujer que escoge, no como compañera en realidad sino como servidora, además de revelar y explotar las funciones biológicas concernientes a la mujer. En cuanto valor, el matrimonio llega a ser determinante para todas las mujeres que desean ser respetadas como personas" (Castellanos, Ciudad Real73).

Los dos espacios anteriores, donde Modesta es la víctima, representan los espacios de explotación propios de su identidad como mujer de clase baja. Mientras que en el primero la relación de abuso es más de índole social; en el segundo es explotada por ser mujer.

El tercero es en el que es posible percibir que la protagonista adopta un papel de victimario. Lo que cambia en este espacio es la estructura social: desaparecen los patrones y los ricos, y las relaciones sociales se dan entre la clase baja; sin embargo, aquí también se desarrolla una estructura de desigualdad: los indios representan el sector más oprimido. Este espacio abarca dos lugares, la carnicería de su comadre Agueda, quien desde el principio aleccionó a Modesta sobre cómo debía atender a la clientela: había que tratar mejor a las criadas de casa rica, luego podía desquitarse con las más humildes, las dependientas como ella; pero el peor trato era para los indios, a quienes había que darles la mercancía más deteriorada sin posibilidad de quejarse. El otro lugar es la salida Moxviquil, donde las atajadoras arrebatan a los indígenas sus pertenencias, pagándoles mucho menos del costo real del producto. El ser mestiza y no india, le permite a Modesta ocupar un lugar superior en la pirámide social: la oportunidad de estar en el lugar de los opresores. En dicho espacio, la protagonista reproduce las situaciones de explotación y abuso que ella experimentó antes y se convierte en victimario; sin embargo, a pesar de que hay una transformación del personaje, su situación como ser explotado no se extingue. En la carnicería trabajaba duramente por un sueldo que no le alcanza para vivir y mantener a sus hijos, y por eso, tiene que madrugar e irse de atajadora. Y en la salida a Moxviquil, cuando estaba luchando con una indígena para arrebatarle el chamarro de lana, llegó otra 
atajadora. Esta mujer más avezada en el oficio, levantó a Modesta para que no siguiera golpeándola, le aventó unas monedas a la joven india y se llevó la mercancía. La protagonista, a pesar de su transformación en victimario, no pierde su posición de víctima en algunas circunstancias.

\section{La dimensión temporal: un pasado en dos tiempos que convergen}

El primer acercamiento al análisis de la dimensión temporal lleva a considerar el tiempo histórico, es decir, la época en la que desarrollan los acontecimientos. A veces esto es claro si hay algún dato que dé una pista para situar el cuento en el tiempo. En "Modesta Gómez” no hay ningún elemento que lo permita. Lo que está narrado pudo acontecer hace un siglo, o incluso, podría suceder ahora, en la medida en que las prácticas racistas y clasistas siguen dándose radicalmente en esa región del país, por tanto, se puede señalar una atemporalidad.

Hay una divergencia entre el tiempo de la historia y el tiempo del discurso. El cuento está narrado en retrospectiva, el narrador utiliza conjugaciones del pretérito para narrar; sin embargo, se pueden diferenciar dentro del tiempo del discurso, dos momentos del pasado: en el primero se relatan distintos sucesos de la vida de la protagonista, a través de elipsis y resúmenes se va pasando por distintas etapas de su vida; el narrador incluye recuerdos y pensamientos de ella y de los demás personajes. Lo narrado dentro de esta clasificación lleva un orden cronológico, sin embargo, se ve interrumpido varias veces por el segundo tiempo en el que se utiliza la analepsis y se intercalan escenas que relatan la iniciación de Modesta en el oficio de atajadora. El segundo tiempo es el eje del relato, ya que mientras transcurre, se evoca el primero. Al final se unen ambos y viene el desenlace del cuento, que concluye con la vivencia de la protagonista como atajadora.

En el análisis del tiempo diegético o tiempo de la historia, se deben considerar dos aspectos: cuánto duran los acontecimientos que se dan en ella y cuál es el orden cronológico de estos que, como 
se vio antes, no llevan la misma secuencia que el discurso. En el cuento la duración de los sucesos narrados es de varios años, inicia cuando la protagonista, siendo una niña, es llevada a casa de los Ochoa: "Me ajenaron desde chiquita. Una boca menos en la casa era un alivio para todos" (Castellanos, Ciudad Real 65), y concluye cuando ella, viuda con tres hijos, se ve obligada a convertirse en atajadora porque su sueldo en la carnicería no le alcanza para alimentarlos. Resulta paradójico que el oficio de atajadora, a pesar de ser una práctica abusiva, le da a Modesta un cierto carácter de heroicidad: hay que madrugar, caminar con el frío y las ganancias son escasas, pero acepta el sacrificio para dar de comer a sus hijos; en cambio, ella fue abandonada por sus padres para tener una boca menos que alimentar.

En la medida que el cuento atraviesa por varios años de la vida de la protagonista, ella pasa por diversas etapas que van forjando un destino de sumisión y un concepto de sí misma como objeto cuya función es la de satisfacer las necesidades de los demás. La primera etapa es su infancia, donde está confinada a ser la cargadora del niño, y por ende a cuidarlo y entretenerlo, así como a hacer las labores propias de una sirvienta. Cuando llega a la adolescencia, la muchacha ha asimilado ya su rol como objeto en función de las necesidades del hombre. Lo prueba su pasividad hacia la violación de Jorgito. La siguiente etapa es el matrimonio donde la gratitud hacia su marido por haberla hecho señora, la lleva a otro sometimiento en el que es víctima de golpes y malos tratos. En la última etapa, la viudez, Modesta sigue asumiendo el rol de las mujeres que viven en función de las necesidades de los demás, ya que tiene la responsabilidad de mantener a sus hijos; sin embargo, aunque en esta etapa está sumida en la pobreza, es una mujer independiente capaz de tomar decisiones propias. Por eso, cuando se inicia como atajadora, a pesar de que una mujer trata de disuadirla hablándole de la dureza del oficio y de que otras la miran con recelo, ella no se deja amedrentar y permanece firme en su decisión. Esto fortalece la idea de que hay un cambio significativo en el personaje. 


\section{La ipseidad de Modesta: de víctima a victimario}

En el análisis espacial y temporal se percibieron algunos rasgos de la identidad de la protagonista y de su proceso de transformación. Ahora se examinará con más detenimiento la identidad inicial del personaje y, de esta forma, se podrán percibir los aspectos esenciales de su transformación.

El narrador aborda poco la descripción del personaje, prácticamente no hay adjetivación que defina cómo es la protagonista; sin embargo, a lo largo del cuento hay varios elementos que permiten inferir algunos rasgos: una mujer mestiza que creció como sirvienta; poco se sabe de su físico, sólo que tenía las piernas torcidas y se puede pensar que era atractiva, ya que cuando salía a la calle, lugar de sus triunfos, recibía de los hombres piropos y declaraciones de amor. Era ilusa: cuando llegó por primera vez a casa de los Ochoa se alegró "de saber que, desde entonces, esa casa magnífica sería también su casa..." (Castellanos, Ciudad Real 66) y, sí fue su casa, solo que ella dormía en un petate viejo y pasaron años hasta que la dejaron dormir en una cama.

De acuerdo con la manera en cómo está narrada la historia, hay dos estados subsecuentes, ligados a la identidad de la protagonista; el primero es un estado pasivo en donde Modesta es concebida como un objeto. Esta idea se refuerza al considerar que en casi toda la primera etapa de su vida narrada, predomina la construcción gramatical de su presencia como un objeto directo, la acción del verbo recae sobre ella: la ajenaron desde chiquita, la sumergieron en una artesa, la violaron, la corrieron, y ya cuando estaba con su marido: la golpeó y la maltrató. En realidad, las conjugaciones verbales donde el personaje se convierte en sujeto son más frecuentes cuando trabaja en la carnicería y cuando va caminando para asumir el oficio de atajadora. Gramaticalmente Modesta deja de ser un objeto y se convierte en el sujeto de sus acciones.

En un análisis somero, la pasividad de la protagonista en las primeras etapas, la hace ver como una mujer sumisa que acepta su condición sin objetar; sin embargo, hay algunos indicios en ella que muestran un espíritu de transgresión. Las travesuras y la intimidad 
con Jorgito, que a doña Romelia le parecía indebida, ya asomaban un espíritu irreverente que se brincaba los límites de las distancias. Pero quizá donde más se ve este aspecto es en los sueños de la protagonista, cuando ella ya empieza a despertar a la sexualidad:

Modesta soñaba, por las noches, con ser la esposa legítima de un artesano. Imaginaba la casita humilde, en las afueras de Ciudad Real, la escasez de recursos, la vida de sacrificios que le esperaba. No, mejor no. Para casarse por la ley siempre sobra tiempo. Más vale desquitarse antes, pasar un rato alegre, como las mujeres malas. La vendería una vieja alcahueta, de las que van a ofrecer muchachas a los señores. Modesta se veía en un rincón del burdel, arrebozada y con los ojos bajos, mientras unos hombres borrachos y escandalosos se la rifaban para ver quién era su primer dueño. Y después, si bien le iba, el que la hiciera su querida le instalaría un negocito para que la fuera pasando. Modesta no llevaría la frente alta, no sería un espejo de cuerpo entero como si hubiese salido del poder de sus patrones rumbo a la iglesia y vestida de blanco. Pero tendría, tal vez, un hijo de buena sangre, unos ahorros. Se haría diestra en un oficio. Con el tiempo correría su fama y vendrían a solicitarla para que moliera el chocolate o curara de espanto en las casas de la gente de pro (67-68).

He citado el párrafo completo ya que en los sueños de Modesta es posible ver en forma más clara los indicios de transgresión. La protagonista creció en un hogar en el que se enarbolaban los valores cristianos (se señaló antes que doña Romelia representaba el estereotipo que perpetúa la sociedad patriarcal en nombre de la moral cristiana); el que la joven en sus sueños prefiriera ser vendida como prostituta a casarse con un joven de su condición social y también que suspirara por pasar un rato alegre como las mujeres malas o que albergara el deseo de ser la querida de un hombre antes que salir de blanco de la casa de sus patrones, representa una transgresión que rompe los límites de una moral impuesta por el núcleo familiar de sus patrones. Ya en estos sueños es posible ver una identidad diferente que se va gestando. 
Entre los deseos silenciosos de Modesta estaba el de tener un hijo de buena sangre, si a esto se aúna que la joven, cuando reconoció a Jorgito forcejeando con ella, se sometió y permitió que el muchacho abusara de ella, pareciera que más que un sometimiento, fue un consentimiento. Sin embargo, se debe considerar que en esta etapa el personaje actuaba como objeto y no como sujeto. Aún en sus sueños, la imagen de ella en el burdel "con los ojos bajos, mientras unos hombres borrachos y escandalosos se la rifaban", determina una actitud más bien pasiva que transgresora.

Frente a doña Romelia, que representa los valores del sometimiento femenino en la estructura social de San Cristóbal, hay otra figura femenina que simboliza el inicio de una nueva etapa: doña Agueda, la dueña de la carnicería. Aunque le paga poco, pertenece a una estructura social de explotación distinta a la de los Ochoa. Es comadre de Modesta, le enseña cómo debe abusar del indio; es ella la que le advierte que sólo las haraganas no pueden con el oficio de atajadora. Es quien le quita el velo de los ojos para mostrarle la verdad de su situación: "Te salió peor el remedio que la enfermedad... Te casaste con Alberto para estar bajo mano de hombre, para que el hijo del mentado Jorge se criara con un respeto. $\mathrm{Y}$ ahora resulta que te quedas viuda, en la loma del sosiego, con tres bocas que mantener y sin nadie que vea por vos" (71).

El personaje de doña Agueda es la iniciadora de Modesta en el papel de victimario, que para la protagonista es el acceso a una estructura donde ella no ocupa el lugar más bajo de la escala social y donde puede reproducir el abuso del que ha sido víctima, por eso cuando está golpeando a la indígena para quitarle el chamarro, le dice: "IIndia desgraciada, me lo tenés que pagar todo junto!", como si esa india fuera el chivo expiatorio de todas las vejaciones que había sufrido. Modesta descubre que ser atajadora no solo representa un ingreso mayor, la violencia contra la indígena le produjo un cierto placer, a pesar de que le fue arrebatado el chamarro por la otra atajadora, ella se sentía contenta: "Sí, volvería mañana y pasado mañana y siempre. Era cierto lo que le decían: que el oficio de atajadora es duro y que la ganancia no rinde. Se miró las uñas ensangrentadas. 
No sabía por qué. Pero estaba contenta" (74). El personaje reproduce la violencia de la cual ella fue objeto; esta acción no representa un valor social positivo, sin embargo, determina la movilidad del personaje hacia una posición distinta de la que le fue impuesta. Lo que se subraya no es un juicio sobre el rol adquirido sino la posibilidad de transgredir una situación permanente de víctima.

Es necesario aclarar que la transformación de Modesta no es algo que elige el personaje, de hecho son sus acciones las que permiten considerar un cambio de identidad. Todos los sucesos narrados, las peripecias, fueron marcando su vida y construyendo su identidad narrativa. Y solo en el desenlace se puede considerar lo que el personaje llegó a ser. En este caso, al lector le corresponde interpretar de dónde provenía la satisfacción de ejercer violencia contra la indígena. Hipotéticamente se puede señalar que la protagonista percibió su propia transformación, el paso de un estado a otro: de la pasividad a la actividad, de ser objeto a ser sujeto, de víctima a victimario. Había transgredido el papel que señala Castellanos como característico de la mujer mexicana, en que ocupa en todas "las ocasiones posibles el sitio de la víctima" (Declaración 114). En el desenlace la protagonista adquiere conciencia de una nueva identidad, es capaz de sentir su ipseidad. Prueba una nueva forma de ser que se había venido gestando y es en ese momento que la reconoce.

\section{Conclusiones}

La clase social y el género llevan a Modesta a seguir algo similar a lo que Nietzsche definió como la moral de los esclavos, donde la obediencia, la compasión, la humildad y la caridad son consideradas virtudes $(30,31)$; estos valores también los pondera el cristianismo. Sin embargo, los sucesos que surgen en la historia van variando las acciones del personaje hasta que deja de ser objeto de escarnio y se convierte en el sujeto que ultraja, que participa del derecho de los amos y siente el bienestar del que ha podido descargar su poder en otro de una condición más baja. Este roce con la violencia no es 
la conquista de la conciencia individual de Modesta, pero sí el reconocimiento de un estado diferente. A esto es posible atribuir su satisfacción en el desenlace.

En la reflexión que conduce a la refiguración a través de este texto, es decir, cuando lo que se aborda en la historia se orienta al mundo real, hay dos aspectos que me parecen fundamentales: el primero, la movilidad de la protagonista que le permite ser diferente al paradigma que le corresponde como mujer mexicana de baja condición, lo que representa una doble transgresión: de género y social. Este mensaje del cuento es fundamental en la medida que determina que se pueden contravenir los roles impuestos. Y el segundo aspecto que invita a la reflexión es cómo el cuento aborda la reproducción de los modelos de violencia: el que es víctima de los malos tratos reproduce la violencia en otros más débiles, esto va creando una pirámide que va extendiendo el abuso en la sociedad.

\section{Bibliografía}

Castellanos, Rosario. Ciudad Real. 2a . ed., Universidad Veracruzana, 1982.

Declaración de fe. Alfaguara, 1996.

Maldonado, Ezequiel. "Los anacronismos de Ciudad Real". Tema $y$ variaciones de literatura, no. 22, enero-junio, 2004, pp. 115-133.

Martínez Sánchez, Alfredo. "Acción e identidad. Sobre la noción de identidad narrativa en Paul Ricoeur", Themata, no. 22, 1999, pp. 195-199.

Nietzsche, Friedrich. Genealogía de la moral. Tr. M. Palmieri, 2a. ed. Mestas, 2003.

Pimentel, Luz Aurora. Relato en perspectiva. Estudio de teoría narrativa. Siglo XXI, 1998.

Ricoeur, Paul. "La identidad narrativa". Sujeto y relato. Antología de textos teóricos, coordinada por María Stoopen Galán, U. Nacional Autónoma de México, 2009, pp. 339-55.

Sandoval Ventura, Juan. Ficción y realidad. Las mujeres en la narrativa de Rosario Castellanos. U. Autónoma de Tlaxcala, 1997. 
Sarfati-Arnaud, Monique. 'Los 'buenos' y los 'malos' en 'Modesta Gómez'. Lectura ideológica de un cuento de Rosario Castellanos". Actas del IX Congreso de la Asociación Internacional de Hispanistas, vol. 2, Vervuert, 1989, 703-09. Centro Virtual Cervantes, www.cervantesvirtual.com/obra/los-buenos-y-los-malos-en-modesta-gomez-lectura-ideologica-de-un-cuento-de-rosario-castellanos/.

Tornero, Angélica. El personaje literario. Historia y borradura. Miguel Ángel Porrúa/ U. Autónoma del Estado de Morelos, 2011. 